\title{
Occupational arthropathy: evidence from the past
}

\author{
H A WALDRON,' MARGARET COX \\ From the Occupational Health Department,' St Mary's Hospital, London W2 INY, and Institute of \\ Archaeology, London WCIH OPY, and British Museum (Natural History), ${ }^{2}$ London SW7 5BD, UK
}

ABSTRACT The relation between osteoarthritis and occupation was examined in a group of skeletons. from the crypt of Christ Church, Spitalfields, in east London used for burial between 1729 and $1869 . \omega$ Of the total of 968 discrete skeletons excavated, 367 had legible coffin plates giving details of name, $\mathrm{D}^{\circ}$ age, sex, and date of death. Various sources were used to find the occupations of the group for which 3 these details were known. As many of those buried in the crypt were Huguenots interest centred on the relation between weaving and osteoarthritis of the hands but none was found using a case-controlos study. Further analyses failed to show a relation between occupation and osteoarthritis of ther shoulder or osteoarthritis at any site. There was a statistically significant association between non-o manual occupations and osteoarthritis of the spine, the reasons for which are not yet clear.

Although mechanical factors undoubtedly play a part in the aetiology of osteoarthritis, ${ }^{12}$ the extent to which repetitive movements carried out during the course of work contribute to the causation of the disease is much more equivocal. There is no doubt that heavy manual work is associated with an increased frequency of joint and muscle pain ${ }^{3}$ and a few studies have shown that the distribution of osteoarthritis varies according to the type of work undertaken. For example, Hadler and his colleagues have shown that the distribution of osteoarthritis in the hands of cotton workers differs according to the tasks carried out. ${ }^{4-6}$

We have been able to study the relation between osteoarthritis and occupation in a group of skeletons excavated from the crypt of Christ Church, Spitalfields, in the east end of London by means of a case-control study.

\section{Material and methods}

The crypt was used for burial between 1729 and 1869 and 968 discrete skeletons have been recovered. Of these, 367 had legible coffin plates giving the name, age, sex, and date of death of the incumbent.

Our analysis was confined to those skeletons with legible coffin plates; we have called these the "named" sample. Each skeleton was studied carefully to determine the presence and distribution of osteoarthritis

Accepted 6 January 1989 using criteria previously described for this type of $\vec{\otimes}$ work. ' In most cases the skeletons were extremely well. ${ }^{\circ}$ preserved and this afforded us a much better opportunity to assess the distribution of osteoarthritis in thes whole skeleton than is often the case with palaeo-⿳亠二口犬 pathological material.

The occupations of the individuals were obtained from various historical sources. The parochial register gave the abode at death of each member of the named? sample and this was used as a cross reference point. Several sources were used to determine occupation and in most cases it was possible to verify the occupation by reference to more than one.

The London trade directories were probably the most valuable source of information. These list the occupations of those in business and state theiro addresses. Many of those in the named sample had? unusual French names since the area had been settleof by Huguenots which made their identification easier.

The Christ Church vestry minute books were infor $\frac{7}{2}$ mative for those living in the Spitalfields area as they listed the names, addresses, and occupations of thoses standing for parochial office.

Baptism records proved useful as they gave the occupation of the baptised infants' father and the family address. Occasionally the coffin plates them selves offered occupational data that could be checkes against other sources. An example would be: "ME George Mills late of the Queenshead, Fashion Street; Obiit 19 June 1827 Aetat 44."

Miscellaneous sources were used as and wher available and for those dying after the beginning of 
civil registration in 1837 , their death certificates stated their occupation.

\section{Results}

The distribution of osteoarthritis and the prevalence rate differed in some respects from those in the contemporary population and will be described in detail elsewhere.

The predominant occupation of the men in the group was that of weaver $(n=29)$. This was not unexpected given that the area contained many Huguenots. On this account we were particularly interested to see whether this occupation was likely to be a determinant of osteoarthritis of the hands, especially in the light of Hadler's studies.

Our first analysis took all men in the named sample with osteoarthritis of the hands as cases. For each case, two controls were drawn at random from among the remaining adults (aged over 21) from the named sample. The occupations of the cases and their controls were then examined to determine whether or not there were any significant differences between the two groups.

Similar analyses were undertaken taking as cases men with osteoarthritis of the shoulder, of the spine, and of osteoarthritis at any site; only a single control was taken for these analyses because of the rather small number of potential controls available.

\section{OSTEOARTHRITIS OF THE HANDS}

Of the 13 men with osteoarthritis of the hands in the named sample, three were weavers (table 1a). Four weavers were among the 26 controls. Although the proportion of weavers among the cases was rather higher than in the controls, the difference was not statistically significant. Nor was there any significant difference when the occupations were grouped into

Table 1 Relation between osteoarthritis of the hands and occupation

\begin{tabular}{lcc}
\hline & \multicolumn{2}{c}{ Osteoarthritis } \\
\cline { 2 - 3 } Occupation & Yes & No \\
\hline$($ a) & 3 & 4 \\
Weaver & 6 & 11 \\
Non-weaver & 4 & 11 \\
Not known & 13 & 26 \\
Total & & \\
$\chi^{2}=0 \cdot 62, \mathrm{p}=\mathrm{NS}$ & & \\
$(b)$ & 6 & 10 \\
Manual occupations & 3 & 5 \\
Non-manual occupations & 4 & 11 \\
Not known & 13 & 26 \\
Total & & \\
$\chi^{2}=0 \cdot 49, \mathrm{p}=\mathrm{NS}$ & & \\
\hline
\end{tabular}

Table 2 Relation between osteoarthritis of the spine and occupation

\begin{tabular}{lcc}
\hline & \multicolumn{2}{c}{ Osteoarthritis } \\
\cline { 2 - 3 } Occupation & Yes & No \\
\hline (a) & 8 & 6 \\
Weaver & 2 & 2 \\
Nonual & 10 & 3 \\
Not known & 4 & 13 \\
Total & 24 & 24 \\
$\chi^{2}=8 \cdot 82, \mathrm{p}=0.03$ & & \\
$(b)$ & & \\
Non-manual occupations & 10 & 3 \\
Remainder & 14 & 21 \\
Total & 24 & 24 \\
$\chi^{2}=3 \cdot 80, \mathrm{p}=0.05$ & & \\
\hline
\end{tabular}

manual and non-manual categories; in this instance six of the cases were in manual occupations and ten of the controls (table 1b).

\section{OSTEOARTHRITIS OF THE SPINE}

There were 24 cases of osteoarthritis of the spine and an equal number of controls was selected. In this analysis the number of weavers was compared with the number of men in manual and non-manual occupationas (table 2a). Although slightly more weavers were among the cases than among the controls (eight compared with six), the most notable feature was the much greater number of non-manual workers among the cases, ten compared with three in the controls. The differences were significant $(p=0.03)$. When non-manual workers were compared with the remainder (table $2 b$ ), the differences were just at the limit of conventional significance $(p=0.05)$.

\section{OSTEOARTHRITIS AT OTHER SITES}

We also considered osteoarthritis of the shoulder and osteoarthritis at any site. There were 33 cases of osteoarthritis of the shoulder and 58 cases with osteoarthritis at any site; for each group only a single control could be taken due to the rather small number in the total sample.

There were six weavers with osteoarthritis of the shoulder and five in that group of controls. Among those with osteoarthritis at any site, 14 of the cases and 12 of the controls were weavers. Neither of these differences was significant.

\section{Discussion}

None of the analyses which we have undertaken here lends support to the view that handloom weaving is associated with a propensity to develop osteoarthritis 
of the hands; indeed, there was no evidence that manual work per se was an aetiological factor in osteoarthritis at this or at any other site. One caveat must be entered here, however-that is, almost all the weavers in our sample were master weavers rather than journeymen weavers. Thus only three of the 14 weavers with osteoarthritis at any site were journeymen, the remainder were all masters who, although having completed an apprenticeship of between seven and 14 years, had almost certainly not touched a loom for a long time.

The most important factor relating the osteoarthritis of the hands in our group was that of age. The mean age of the 13 cases was 71.6 years whereas in the controls the mean age was $57.6(p<0.05)$. This suggests that the disease in the hands was related more to aging than to occupation.

One unexpected finding from our study was the significantly increased number of non-manual workers among the cases with osteoarthritis of the spine. At first glance, this seems to be at variance with the generally held view that the likelihood of developing osteoarthritis is directly related to the physical effort involved in work. It is possible, but unlikely, that we misclassified some of the occupations, but if this were the case the bias might have been expected to show in other analyses and this does not seem to offer the most plausible explanation. What it was that predisposed these non-manual workers to develop osteoarthritis of the spine we cannot say but further work may perhaps suggest something to us.

No other occupational group was sufficiently large to allow for any formal statistical analysis. The next largest group in size to the weavers was carpenters of whom there were only four. There were three butchers and three rectors and of the latter, two had osteoarthritis of the hands but it seems improbable that we could invoke an occupational cause for this.

The health of the weavers of Spitalfields received little attention from contemporaneous authors. Mit- chell in his report which was contained within the 3

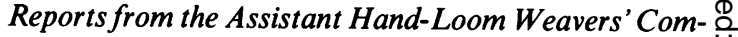
missioners in 1840 noted that their small stature

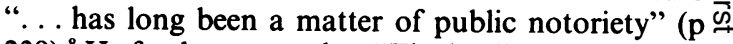
239). ${ }^{8} \mathrm{He}$ further states that "The leading characteristics of the weaver's constitution is feebleness ... The 흠 occupation of weaver ... exposes him to diseases of $\frac{\bar{N}}{7}$ the stomach, and to consumption. In his work he $\stackrel{\mathbb{Q}}{\odot}$ presses against his stomach, which cannot fail to be injurious." There was said to be a great mortality among the children of weavers and "Diseases peculiar. to females are aggravated amongst girls and married $\vec{\omega}$ women by the injury done to the constitution by the o work of the loom, more particularly at an early age. Difficult parturitions are more frequent amongst the $\exists$ weavers' wives than amongst the rest of the commun- के ity" (p 241). No mention is made of any arthritic os consequences of their work and those conditions which were said to be common are not amenable to study at this late stage.

\section{References}

1 Nuki G. The aetiopathogenesis of osteoarthrosis. London: Pitman Medical, 1980.

2 Peyron JG. Review of the main epidemiologic-etiologic evidence that implies mechanical forces as factors in osteoarthritis. Engineering in Medicine 1986;15:77-9.

3 Lawrence J. Rheumatism in populations. London: Heineman, 1977.

4 Hadler NM. Industrial rheumatology. Arthritis Rheum 1977;20:1019-25.

5 Hadler NM, Gillings DB, Imbus HR, et al. Hand structure and function in an industrial setting. Influence of three patterns of $\overline{\bar{O}}$ stereotyped, repetitive usage. Arthritis Rhem 1978;21:210-20.

6 Hadler NM. The variable of usage in the epidemiology of osteoarthrosis, In: Peyron JG, ed. Epidemiology of osteoarthritis. Basle: Geigy, 1980:164-71.

7 Rogers J, Waldron T, Dieppe P, Watt I. Arthropathies in palaeopathology: the basis of classification according to most $\mathbb{D}$ probable cause. Journal of Archaeological Science 1987; 14:179-93.

8 Mitchell J. Spitalfields. In: Reports from assistant hand-loom weavers' commissoners. Part II. London: HMSO, 1840:213-76. 